\title{
Bronchial Associated Lymphoid Tissue Lymphoma in Systemic Lupus Erythematosus Successfully Treated with Rituximab
}

Eid AIQurashi' ${ }^{1,2}$, Shikha Mittoo ${ }^{3}$, Zahi Touma ${ }^{4}$, Shane Shapera ${ }^{5}$, Theodore K Marras ${ }^{5,6}$ and Muhammad Sohail Anjum ${ }^{7 *}$

${ }^{1}$ Department of Medicine, Division of Respirology, King Abdullah Medical City, Saudi Arabia

${ }^{2}$ Department of Medicine, Division of Respirology, University of Toronto, Toronto General Hospital, Canada

${ }^{3}$ Division of Rheumatology, Department of Medicine, University of Toronto, Mount Sinai Hospital, Canada

${ }^{4}$ Division of Rheumatology, Department of Medicine, University of Toronto, Toronto Western Hospital, Canada

${ }^{5}$ Department of Medicine, Division of Respirology, University of Toronto, Toronto General Hospital, Canada

${ }^{6}$ Division of Respirology, Universty of Toronto, Toronto Western Hospital, Medicine, Canada

${ }^{7}$ Department of Medicine, King Abdullah Medical City, Saudi Arabia

\begin{abstract}
We present, for the first time to our knowledge, a patient with Systemic Lupus Erythematosus (SLE) with pulmonary Bronchial-Associated Lymphoid Tissue (BALT) lymphoma, refractory to chemotherapy but after a single four-week course of rituximab experienced significant regression of pulmonary lesions and remained progressionfree six months post- treatment. This case report demonstrates the promising role for rituximab in refractory BALT lymphoma.
\end{abstract}

Keywords: Systemic lupus erythematosus; Bronchial-associated lymphoid tissue (BALT) lymphoma; Rituximab

\section{Introduction}

Marginal zone lymphomas arise from memory B cells in the marginal zone of lymphoid tissue [1]. Marginal zone lymphoma, a subtype of Non-Hodgkin's lymphoma, includes extra nodal marginal zone B cell lymphoma of the Mucosa Associated Lymphoid Tissue (MALT) type (MALT-type lymphoma, MALT lymphoma), nodal marginal zone B cell lymphoma and splenic marginal zone B cell lymphoma [2].

Extra nodal MALT lymphoma can develop in the setting of chronic local inflammatory disorders or autoimmune diseases such as Sjogren Syndrome (SS), rheumatoid arthritis and Systemic Lupus Erythematosus (SLE) [3,4]. It has been speculated that pulmonary MALT lymphomas might develop secondary to chronic antigenic stimulation of the lungs from long-term exposure to smoking, infections, or autoimmune diseases $[5,6]$.

The optimal management of BALT lymphoma is not well established. Recommended treatment options range from complete surgical excision to surgery followed by radiotherapy or chemotherapy alone but the optimal therapy remains unclear [7-9].

BALT lymphoma cells express CD20 antigen, and therefore, the use of rituximab may be considered and appears attractive. Few short series and single case reports showed that rituximab as a single agent or as an adjunct to other therapy is safe, with significant activity in untreated or relapsed BALT lymphoma patients [5,10-16].

Here we report a case of a 33 year-old-man SLE and BALT lymphoma who achieved complete resolution of pulmonary lesions after four cycles of rituximab treatment.

\section{Case Report}

A 33 year-old man was referred to respirology in September 2007 for a 2 years history of unexplained exertional dyspnoea and dry cough. On further enquiry, the patient reported episodic flares of his symptoms that were thought to be secondary to recurrent pneumonias and effectively treated with courses of antibiotics and high doses of oral corticosteroids.
His past medical history was notable for SLE, antiphospholipid syndrome, diabetes mellitus, hypertension and fibromyalgia.

Clinical features suggestive of systemic lupus erythmatosus were mucosal ulceration, arthritis, psychosis, thrombocytopenia and positive ANA, Anti-Ds DNA. Treatment consisted of prednisolone (20 mg/day), azathioprine (150 mg/day) and hydroxychloroquine (400 $\mathrm{mg} /$ day).

The patient had worked as a welder and metal worker, but did not machine hard metals. He has been off work for 3 years due to poor health. He had smoked one pack of cigarette daily for 15 years and had quit smoking 3 years ago. On examination, auscultation of the chest revealed scattered inspiratory crackles. Pulmonary Function Test (PFT) showed moderate obstruction with mild reduction of Forced Vital Capacity (FVC) (Table 1). A high resolution CT chest demonstrated scattered cysts and small bullae in both lungs with mild ground glass appearance and few bilateral small nodules. The CT chest findings were consistent with chronic interstitial pneumonitis secondary to SLE. The patient was admitted to the inpatient unit and treated with a course of steroids. The course was complicated by another infective pneumonic episode treated successfully with broad spectrum antibiotics. After

\begin{tabular}{|l|l|l|l|}
\hline & $\mathbf{2 0 0 7 / 0 9}$ & $\begin{array}{l}\mathbf{2 0 1 1 / 0 8} \\
\text { (pre-RTX) }\end{array}$ & $\begin{array}{l}\text { 2011/11 } \\
\text { (post-RTX) }\end{array}$ \\
\hline FVC (\% predicted) & $3.3(75)$ & $3.3(75)$ & $3.8(84)$ \\
\hline FEV1 (\% predicted) & $2.3(62)$ & $1.7(47)$ & $2.1(58)$ \\
\hline FEV1/FVC\% & 70 & 52 & 55 \\
\hline
\end{tabular}

Table 1: Pulmonary function results Pre- and Post-rituximab (RTX: rituximab, FVC forced vital capacity, FEV1: forced expiratory volume in 1 second).

*Corresponding author: Muhammad Sohail Anjum, Department of Medicine King Abdullah Medical City, Makkah, Saudi Arabia, Tel: +966-55-2385120; E-mail: friendsohail712@gmail.com

Received November 10, 2013; Accepted January 24, 2014; Published January 26, 2014

Citation: AIQurashi E, Mittoo S, Touma Z, Shapera S, Marras TK, et al (2014) Bronchial Associated Lymphoid Tissue Lymphoma in Systemic Lupus Erythematosus Successfully Treated with Rituximab. J Clin Case Rep 4: 336. doi:10.4172/2165-7920.1000336

Copyright: @ 2014 AIQurashi E, et al. This is an open-access article distributed under the terms of the Creative Commons Attribution License, which permits unrestricted use, distribution, and reproduction in any medium, provided the original author and source are credited. 
a few days, the patient improved clinically and discharged home on prednisone $20 \mathrm{mg} /$ day.

Within one month, the patient was readmitted with progressive worsening dyspnoea and persistent cough. A repeated CT chest showed a new infiltrate at the lingula. Lung biopsy revealed aggressive MALT lymphoma. The recurrent episodes of pneumonia were sequlae of obstructive aggressive MALT lymphoma causing impaired clearance of respiratory secretions. Oncologist deferred the chemotherapy as it would further increase the risk for respiratory infection.

The treatment plan was modified in November 2009, because the patient continued to experience frequent episodes of chest exacerbations that required antibacterial courses (approximately two weeks per month) and bursts of higher doses of prednisone doses. The episodes were associated with reduction of his Forced Expiratory Volume in one second (FEV1) from $2.4 \mathrm{~L}(64 \%)$ to $1.8 \mathrm{~L}$ (50\%). The patient was treated with chlorambucil for nearly 1 year without significant improvement in his respiratory symptoms, PFT or CT chest findings.

In August 2011, the patient was admitted to the hospital with right lung consolidation. His CT chest showed right upper lobe with bilateral lower lobes peribronchial opacities with scattered nodular infiltrate and stable bilateral cystic lesions. His Broncho Alveolar Lavage (BAL) was positive for Pseudomonas aeroginosa and endobronchial biopsy from the right upper lobe bronchus was suggestive for MALT lymphoma with positive staining for B-cell marker CD20. In September 2011, Rituximab was initiated. No side effects including infections were observed for 6 months after rituximab therapy. After 4 infusions of Rituximab (375 mg/m² each), he had dramatic improvement of shortness of breath, cough and his body pain. Post rituximab CT chest from October of 2011 showed complete resolution of bilateral opacities (Figure 1). Post rituximab PFT in November of 2011 showed significant improvement of his FEV1 which increased from $1.7 \mathrm{~L}(47 \%)$ to $2.1 \mathrm{~L}(58 \%)$ (Table 1). He had no pulmonary complaints at the time of his last visit in March of 2012.

\section{Discussion}

Primary non-Hodgkin lymphoma of the lung is a rare entity. The

Pre-rituximab
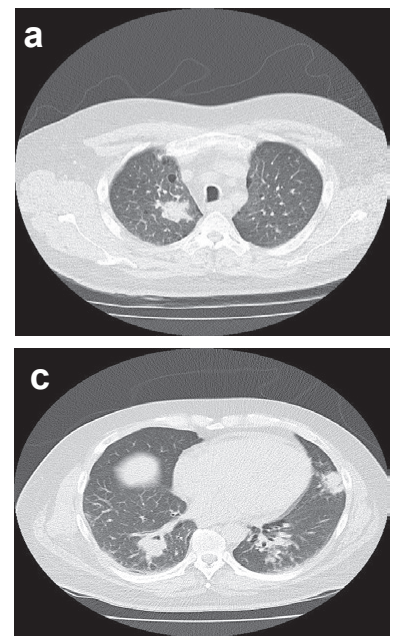

Figure 1: Chest computed tomography pre-rituximab $(A, B)$ and post-rituximab $(C, D)$ showed complete resolution of right upper lobe and bilateral lower lobe nodular opacities. most common type of primary pulmonary lymphoma is the extranodal marginal zone B-cell lymphoma of MALT (mucosa-associated lymphoma tissue) type, which arises from Bronchus-Associated Lymphoid Tissue (BALT) [15].

BALT lymphoma represents approximately $70 \%-90 \%$ of all primary lung lymphomas, $10 \%$ of all MALT lymphomas, $4 \%$ of extranodal NHL, and $0.5-1 \%$ of primary pulmonary malignancies.

The overall prognosis of BALT lymphoma has constantly been reported as favourable, with 5 -year overall survival is about $80 \%$ with different treatment modalities such as surgery, watchful waiting, radiotherapy, chemotherapy, immunotherapy or chemoimmunotherapy, but the risk of relapse seems to be constant, with an estimated incidence of $35 \%$ at five years $[5,7,17]$. The risk of NHL in patients with SLE was found to be increased 3-4 folds compared to general population. Numerous risk factors were reported, but the reasons for the association remain largely speculative. Infections, immunosuppressive and cytotoxic drugs are potential mediators of an association between SLE and malignancy. In our case, the possible hypothesis behind BALT lymphoma is the repeated infections leading to persistent antigen-stimulation, chronic inflammation, and uncontrolled B-cell proliferation, resulting in development of BALT lymphoma. Therapy for BALT lymphoma is still debated mainly because the reported series are small and heterogeneous. The small incidence and prevalence of the disease make it difficult for large randomized clinical trials to be conducted [2]. Treatment of BALT lymphoma includes observation only, surgical resection alone or combination with chemotherapy or radiotherapy. Surgery serves both diagnostic and therapeutic purpose and may be the treatment of choice for localized disease [5]. However, BALT lymphoma is frequently a multifocal disease where radical resection may not be a practical solution. For asymptomatic and non-surgical candidates watchful waiting or single agent chemotherapy could be a reasonable approach. Radiotherapy or single-agent chemotherapy can be used as an alternative to surgery or as adjunctive treatment for incompletely resected disease [5]. Combination chemotherapy (CHOP-containing regimen: cyclophosphamide, doxorubicin, vincristine, prednisone) regimen may be considered in symptomatic patients with bulky, disseminated or recurrent disease [11].

The therapeutic role of rituximab as a single agent for treatment of BALT lymphoma is not well-established. Different protocols have been reported in several case reports and case series. Different objective responses were reported and included stable disease, partial and complete response.

Our review of the literature identified only 11 patients with BALT lymphoma who received rituximab therapy as single agent (Table 2); in 9 patients, rituximab was used as first-line monotherapy and 2 patients were treated with rituximab monotherapy as a second-line therapy, having failed conventional chemotherapy. The duration of rituximab therapy was reported in 10 patients. Seven patients were treated with four doses of rituximab. Rituximab provided good clinical response; complete response was achieved in 2 patients, partial response in 4 and 1 patient did not progress while on rituximab. Three patients treated with extended rituximab schedules with a complete response in 2 and partial response in 1. Our patient, who was chlorambucil resistant, had marked regression of pulmonary lesions after treatment with 4 cycles of rituximab. The therapy resulted in marked improvement of disease-related symptoms, PFT, and radiographic findings. To our knowledge, we present the first case of SLE, with the development of BALT lymphoma, treated successfully with rituximab. In this 
Citation: AlQurashi E, Mittoo S, Touma Z, Shapera S, Marras TK, et al. (2014) Bronchial Associated Lymphoid Tissue Lymphoma in Systemic Lupus Erythematosus Successfully Treated with Rituximab. J Clin Case Rep 4: 336. doi:10.4172/2165-7920.1000336

\begin{tabular}{|l|l|l|l|l|}
\hline Author & Patient & Doses & $\begin{array}{l}\text { Objective } \\
\text { response }\end{array}$ & Line \\
\hline Ahmed et al. [5] & 1 & 4 & PR & $1^{\text {st }}$ \\
\hline Stefanovic et al. [10] & 2 & 4 & PR & $1^{\text {st }}$ \\
\hline & 3 & 4 & CR & $1^{\text {st }}$ \\
\hline & 4 & 4 & PR & $1^{\text {st }}$ \\
\hline Arnaoutakis and Oo [11] & 5 & 4 & SD & $1^{\text {st }}$ \\
\hline Chong et al. [13] & 6 & 4 & CR & $1^{\text {st }}$ \\
\hline Seker et al. [14] & 7 & 4 & PR & $2^{\text {nd }}$ \\
\hline Bilici et al. [15] & 8 & 6 & CR & $1^{\text {st }}$ \\
\hline Arkenau et al. [16] & 9 & 32 & CR & $1^{\text {st }}$ \\
\hline Solomonov et al. [12] & 10 & 36 & PR & $1^{\text {st }}$ \\
\hline Table ResDe & 11 & NA & CR & $2^{\text {nd }}$ \\
\hline
\end{tabular}

Table 2: Response to single-agent rituximab in patients with BALT lymphomas (PR: Partial Response, CR: Complete Response, SD: Stable Disease, NA: Not Available).

report, rituximab seems to be a safe and effective treatment for BALT lymphoma when standard chemotherapy has failed or contraindicated. Furthermore, it has helped in controlling lupus symptoms. The place and the duration of treatment of rituximab need to be investigated more by prospective large studies in the future.

\section{References}

1. Zucca E, Bertoni F, Stathis A, Cavalli F (2008) Marginal zone lymphomas. Hematol Oncol Clin North Am 22: 883-901.

2. Harris NL, Jaffe ES, Stein H, Banks PM, Chan JK, et al. (1994) A revised European-American classification of lymphoid neoplasms: a proposal from the International Lymphoma Study Group. Blood 84: 1361-1392.

3. Bernatsky S, Ramsey-Goldman R, Rajan R, Boivin JF, Joseph L, et al. (2005) Non-Hodgkin's lymphoma in systemic lupus erythematosus. Ann Rheum Dis 64: 1507-1509.

4. Smedby KE, Hjalgrim H, Askling J, Chang ET, Gregersen H, et al. (2006) Autoimmune and chronic inflammatory disorders and risk of non-Hodgkin lymphoma by subtype. J Natl Cancer Inst 98: 51-60.

5. Ahmed S, Kussick SJ, Siddiqui AK, Bhuiya TA, Khan A, et al. (2004) Bronchial- associated lymphoid tissue lymphoma: a clinical study of a rare disease. Eur $\mathrm{J}$ Cancer 40: 1320-1326.

6. Kurtin PJ, Myers JL, Adlakha H, Strickler JG, Lohse C, et al. (2001) Pathologic and clinical features of primary pulmonary extranodal marginal zone B-cell lymphoma of MALT type. Am J Surg Pathol 25: 997-1008.

7. Ferraro P, Trastek VF, Adlakha H, Deschamps C, Allen MS, et al. (2000) Primary non-Hodgkin's lymphoma of the lung. Ann Thorac Surg 69: 993-997.

8. Cordier JF, Chailleux E, Lauque D, Reynaud-Gaubert M, Dietemann-Molard A, et al. (1993) Primary pulmonary lymphomas. A clinical study of 70 cases in nonimmunocompromised patients. Chest 103: 201-208.

9. Cadranel J, Wislez M, Antoine M (2002) Primary pulmonary lymphoma. Eur Respir J 20: 750-762.

10. Stefanovic A, Morgensztern D, Fong T, Lossos IS (2008) Pulmonary margina zone lymphoma: a single centre experience and review of the SEER database. Leuk Lymphoma 49: 1311-1320.

11. Arnaoutakis K, Oo TH (2009) Bronchus-associated lymphoid tissue lymphomas. South Med J 102: 1229-1233.

12. Solomonov A, Zuckerman T, Goralnik L, Ben-Arieh Y, Rowe JM, et al. (2008) Non-Hodgkin's lymphoma presenting as an endobronchial tumor: report of eight cases and literature review. Am J Hematol 83: 416-419.

13. Chong EA, Svoboda J, Cherian S, Andreadis C, Downs LH, et al. (2005) Regression of pulmonary MALT lymphoma after treatment with rituximab. Leuk Lymphoma 46: 1383-1386.

14. Seker M, Bilici A, Ustaalioglu BO, Salman T, Sonmez B, et al. (2009) Extended rituximab schedules may result in increased efficacy in pulmonary malt lymphoma. Leuk Res 33: e154-156.

15. Bilici A, Seker M, Ustaalioglu BB, Canpolat N, Salepci T, et al. (2011) Pulmonary BALT Iymphoma successfully treated with eight cycles weekly rituximab: report of first case and F-18 FDG PET/CT images. J Korean Med Sci 26: 574-576.

16. Arkenau HT, Gordon C, Cunningham D, Norman A, Wotherspoon A, et al (2007) Mucosa associated lymphoid tissue lymphoma of the lung: the Royal Marsden Hospital experience. Leuk Lymphoma 48: 547-550.

17. Raderer M, Wohrer S, Streubel B (2006) Assessment of disease dissemination in gastric compared with extragastric mucosa-associated lymphoid tissue lymphoma using extensive staging: a single-center experience. J Clin Oncol. 24:3136-3141. 